\title{
Oesophago-bronchial fistula in the adult
}

\author{
M. V. B R A I M B R I D GE AND H. I. KEITH \\ From the Brompton and London Chest Hospitals, and the Surgical Unit, St. Thomas' Hospital, London
}

Fistulae between the oesophagus and bronchi may be congenital, traumatic, inflammatory or neoplastic. Congenital fistulae associated with atresia of the oesophagus present dramatically in infancy, and their diagnosis and treatment are established. Fistulae without atresia are more insidious in their effects, and patients may reach adult life before the condition is recognized, particularly if the bronchus involved is lobar rather than main.

Only 20 descriptions of congenital fistulae between the oesophagus and the lobar bronchi in which the diagnosis has been made in adult life have been found after a search of the literature, and the purpose of this communication is to present three more cases to illustrate a classification that may be useful aetiologically and therapeutically.

\section{CLASSIFICATION}

Four types of congenital fistulae between the oesophagus and the lobar bronchi can be distinguished (Fig. 1). The first (type I) is associated with a wide-necked congenital diverticulum of the oesophagus. Stasis may occur in the dependent tip which becomes inflamed and perforates into the lung. Although there is a congenital background, the fistula is inflammatory in origin, and it may be difficult to distinguish the diverticulum from the traction variety (Ribbert, 1902 ; Hewitson, 1961).
I

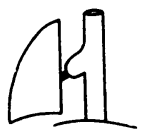

Wide necked diverticulum with inflammatory fistula at tip

II

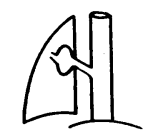

Fistula with cyst
I

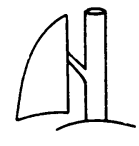

Simple fistula

IV

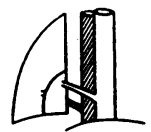

Fistula with sequestrated segment
FIG. 1. Classification of congenital oesophago-bronchial fistula without atresia of the oesophagus.
Type II is the simplest. A short track runs directly from the oesophagus to the lobar or segmental bronchus.

Type III consists of a fistulous track connecting the oesophagus to a cyst in the lobe, which in turn communicates with the bronchus.

In Type IV the fistula runs into a sequestrated segment which is recognized by the presence of a systemic arterial supply from the aorta. The sequestration connects by one or more tracks with the bronchus.

In this series there were $13(57 \%)$ type II cases, six $(26 \%)$ type III, and four $(17 \%)$ type IV.

\section{MATERIAL}

CASE 1 (Simple fistula-type II) A 42-year-old woman had had two attacks of pneumonia at the ages of 8 and 15 years. She had had indigestion for many years, thought to be due to a peptic ulcer, and a persistent cough particularly after liquid meals. On direct questioning she said she had never been able to lie on her right side or drink lying down, because of choking.

On examination she had râles at the right base and a normal chest radiograph. Endoscopy revealed redness and scarring of the right lower lobe bronchus posteriorly, but the fistula was not seen in either the bronchus or oesophagus. A barium swallow demonstrated the fistula to the bronchus (Fig. 2).

At right thoracotomy by Sir Thomas Holmes Sellors at the Middlesex Hospital, a fistula $10 \mathrm{~mm}$. long and $3 \mathrm{~mm}$. wide connected the oesophagus to a pin-point opening in the right lower lobe bronchus. The fistula was divided and both openings were closed and separated by a pleural flap. Subsequently the patient put on weight and could lie on each side and drink without trouble.

CASE 2 (Fistula with cyst-type III) A 19-year-old motor mechanic had had a persistent cough and recurrent pneumonia since the age of 1 year: he was diagnosed bronchographically as having mild bronchiectasis. His main complaint on admission was of coughing when lying under a car at his work. On direct questioning he admitted to regurgitation of food and some burning in the throat all his life.

On examination no abnormality was found. The plain chest radiograph was normal, and broncho- 


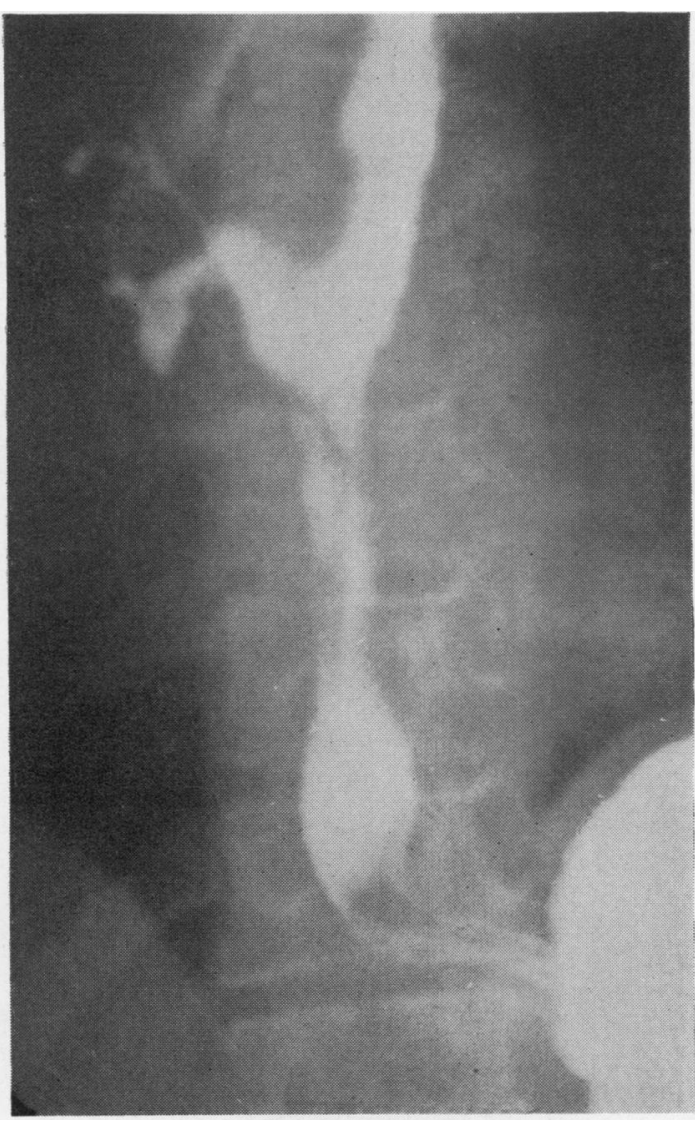

FIG. 2. Case 1. Barium swallow showing fistulous track communicating with the right lower lobe bronchus.

graphy showed slight dilatation of the right basal bronchi. A barium swallow revealed a fistula $5 \mathrm{~mm}$. in diameter and 3 in. above the diaphragm between an otherwise normal oesophagus and the right lower lobe bronchus, and the presence of a cyst whose relationship to the fistula was not clearly demarcated.

At right thoracotomy by Mr. Vernon Thompson at the London Chest Hospital, the right lower lobe was adherent to the chest wall, with inflammation in the posterior segment. A fistulous track, $4 \mathrm{~mm}$. wide and $5 \mathrm{~mm}$. long with no external evidence of inflammation, connected the oesophagus to the right lower lobe in the region of the apical lower segment. The fistula was divided, the oesophageal opening closed, and a right lower lobectomy performed. The patient's symptoms were cured.

The specimen showed that the fistula entered a pear-shaped cyst in the lobe, $2 \mathrm{~cm}$. in diameter, lined by ciliated columnar epithelium, in the wall of which were openings into the posterior and lateral basal bronchi (Figs. 3 and 4). The fistula was lined by columnar epithelium except at the oesophageal end

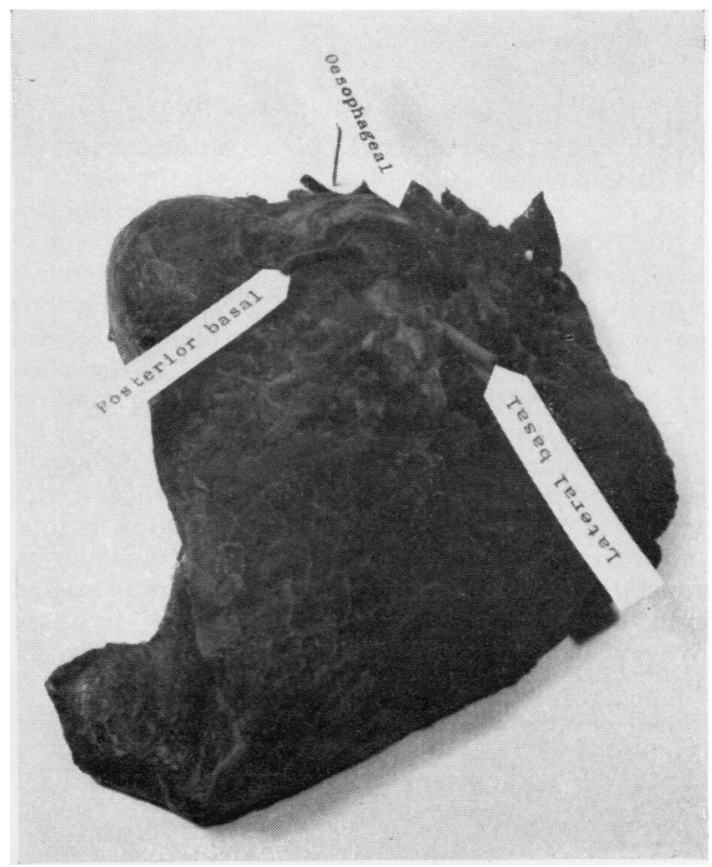

FIG. 3. Case 2. Right lower lobe showing communications from cyst to oesophagus, lateral and posterior basal bronchi.

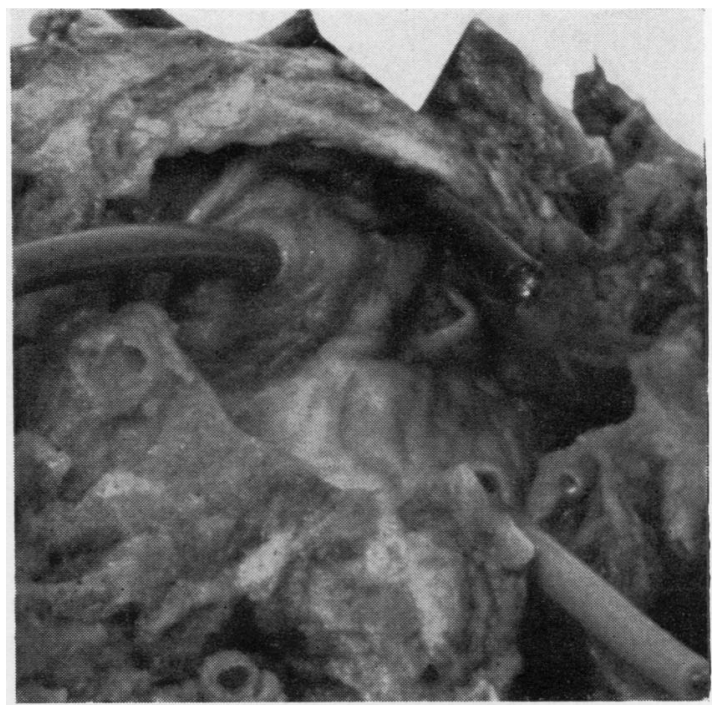

FIG. 4. Case 2. Closer view of cyst with markers as in Figure 3. 
where it was squamous, and there was no inflammatory infiltration.

CASE 3 (Fistula with cyst-type III) A 34-year-old woman had had three attacks of left-sided pneumonia and pleurisy since the age of 2 years. She had had routine chest radiographs for six years since changes at the left base compatible with old pleurisy had been found, and two months before admission a cavity was demonstrated in the left lower lobe. She had recurrent colds and produced an ounce of purulent sputum daily. Direct questioning after the diagnosis had been made elicited a story of choking on swallowing liquids.

On examination there were diminished breath sounds and dullness at the left base. The chest radiograph showed a partially collapsed left lower lobe with a cavity posteriorly (Figs. 5 and 6 ), and during bronchography contrast medium inadvertently passed down the oesophagus and along a track into the cavity which connected with the lower lobe (Fig. 7). There was minimal basal bronchial dilatation. A barium swallow confirmed the findings. Bronchoscopy was normal, but oesophagoscopy showed a crescentshaped valvular opening on the left posterior wall of the oesophagus $38 \mathrm{~cm}$. from the upper alveolus.

At thoracotomy by Mr. Paneth at the Brompton Hospital, the pleura was adherent over an apparently normal lower lobe, and a sac $3 \mathrm{~cm}$. in diameter was attached to, and communicated with, the lateral basal segment. A fistula $6 \mathrm{~mm}$. in diameter and $1.5 \mathrm{~cm}$. long joined the oesophagus to the sac. There were enlarged lymph nodes at the hilum of the lung but none around the oesophagus. The fistulous track was divided close to the oesophagus and a left lower lobectomy was performed. The patient had no symptoms subsequently.

The specimen showed a thick-walled fistulous track passing from the oesophagus into a thin-walled cyst which in turn communicated with the bronchial tree (Figs. 8 and 9). The fistula and cyst were lined by squamous epithelium of the oesophageal type. The fistula was surrounded by bundles of smooth muscle arranged in a bizarre manner, and the cyst was surrounded by fibroelastic tissue without muscle.

\section{DISCUSSION}

The literature has revealed 20 cases of congenital fistulae between the oesophagus and the lobar

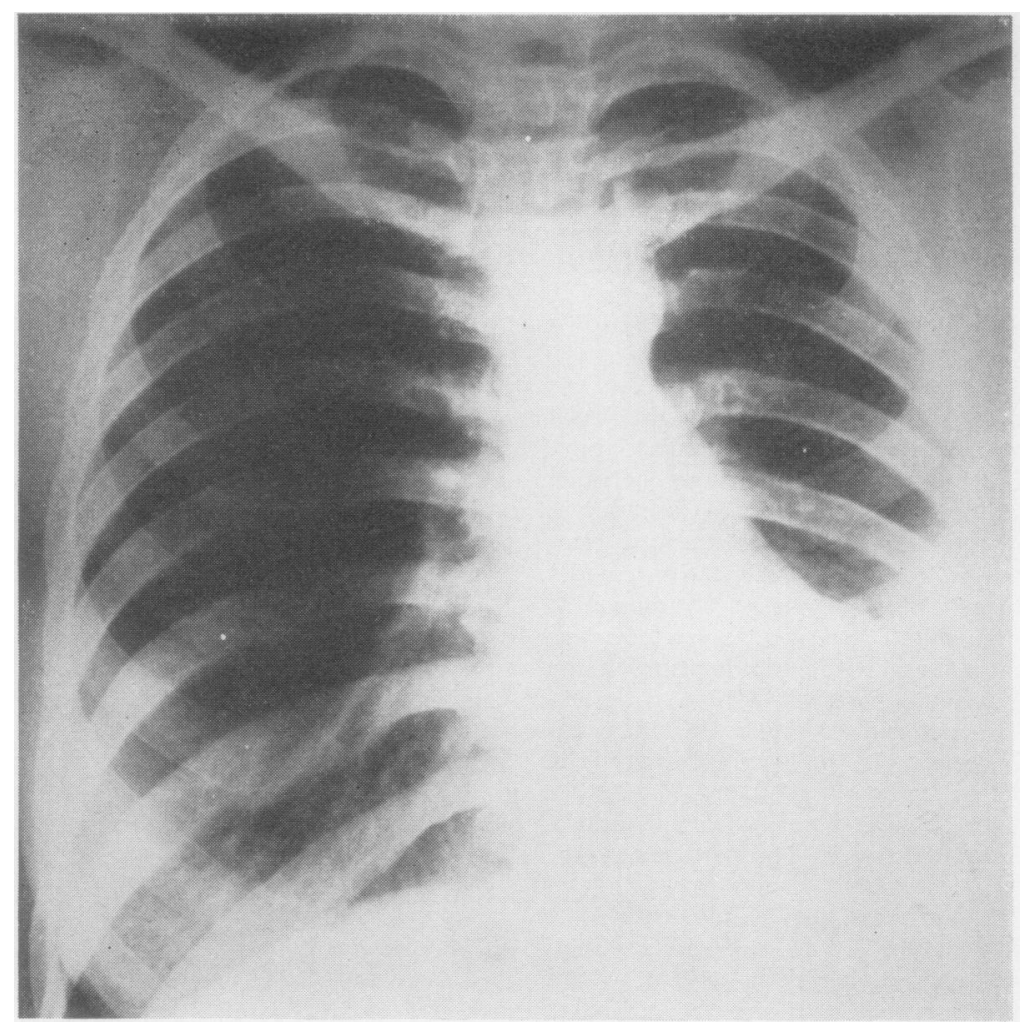

FIG. 5. Case 3. Chest radiograph showing partially collapsed left lower lobe. 


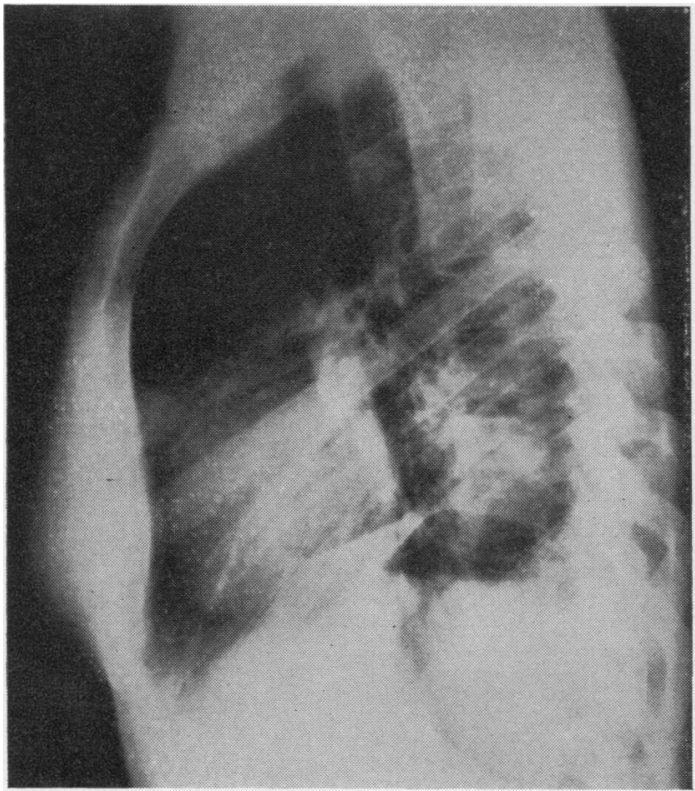

FIG. 6

FIG. 6. Case 3. Lateral radiograph showing cavity in left lower lobe above gastric shadow.

FIG. 7. Case 3. Opaque swallow with track and cyst in left lower lobe demonstrated.

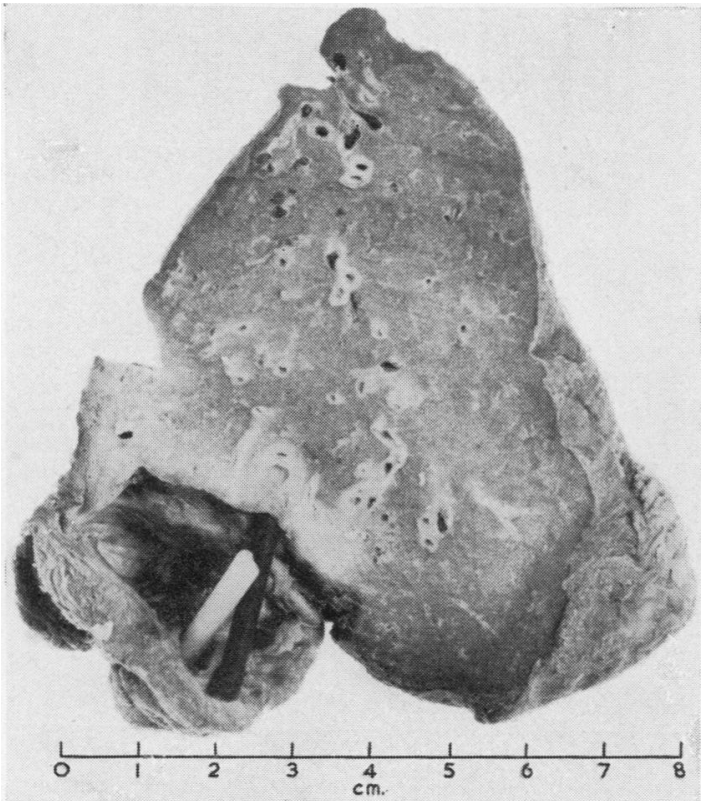

FIG. 8. Case 3. Left lower lobe: white marker in oesophageal connexion of cyst; black marker in bronchial communication.

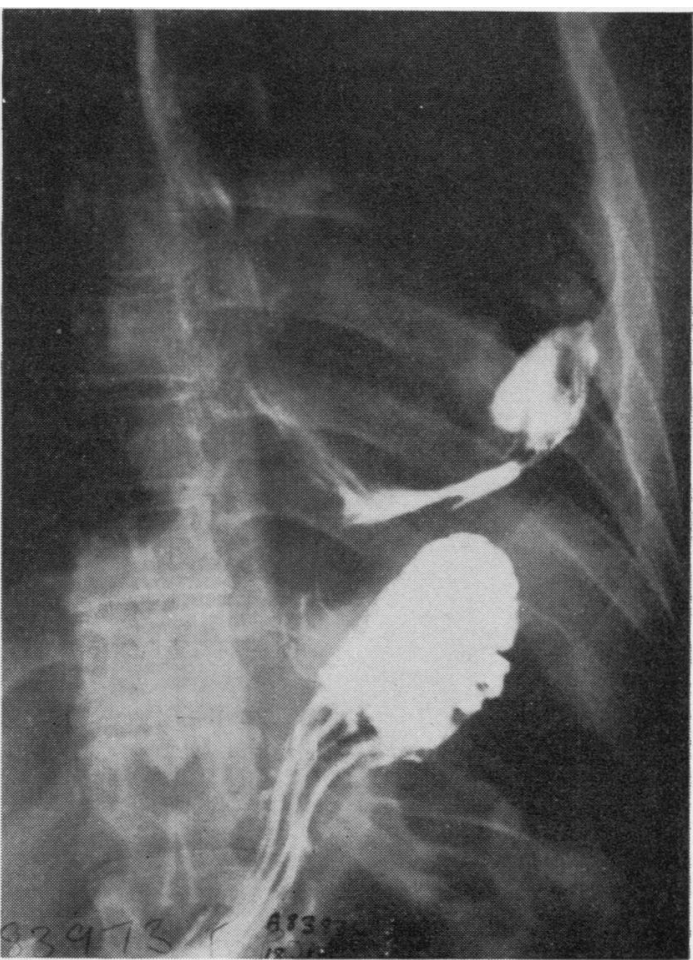

FIG. 7

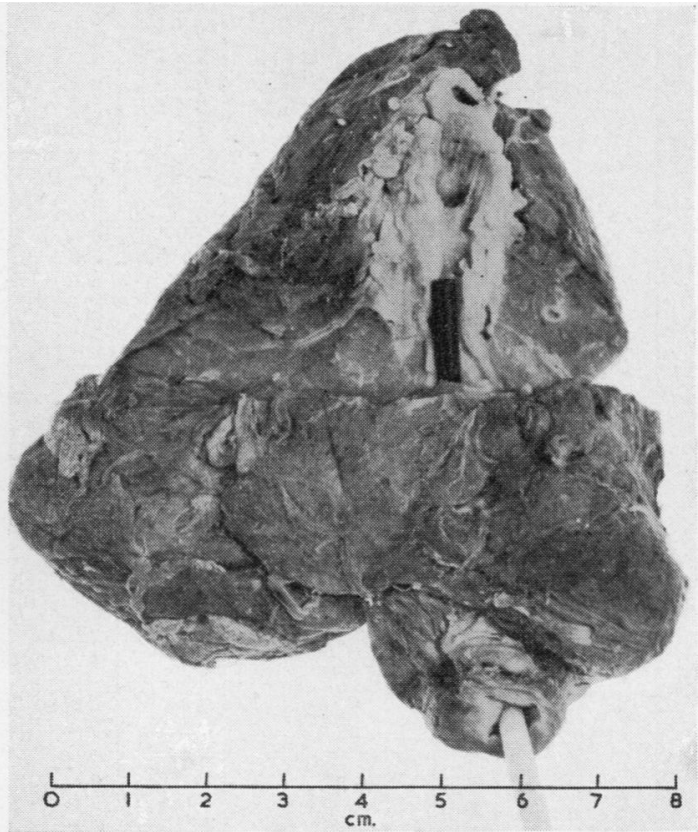

FIG.9. Case 3. Left lower lobe. Oesophageal and bronchial communications of cyst shown by markers. 
M. V. Braimbridge and H. I. Keith

국응

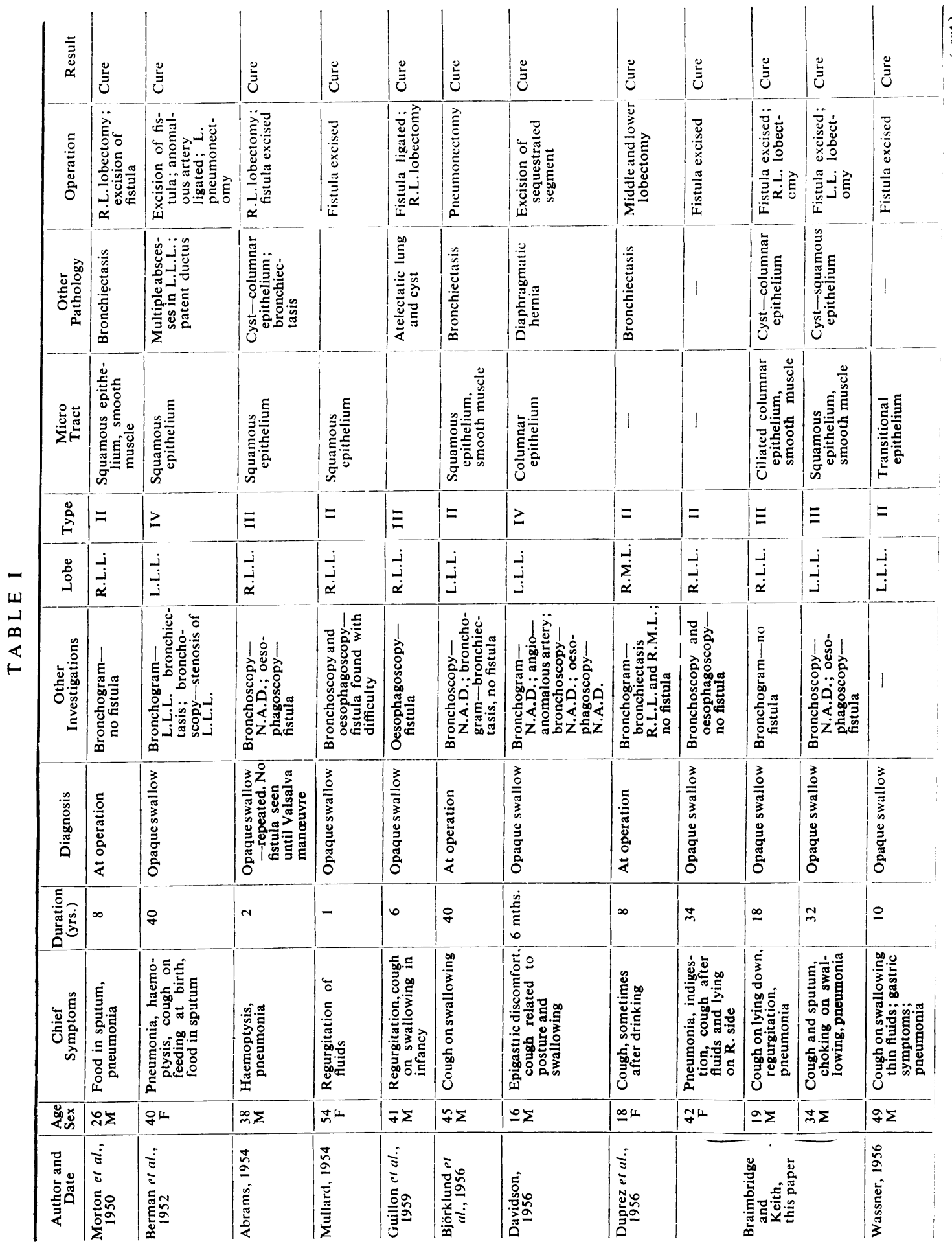

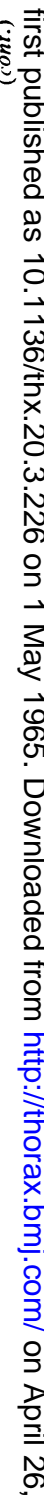

옹

స్ట

হ

$\stackrel{ }{\frac{1}{D}}$

$\stackrel{9}{\hookrightarrow}$

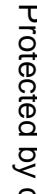

응

흘 


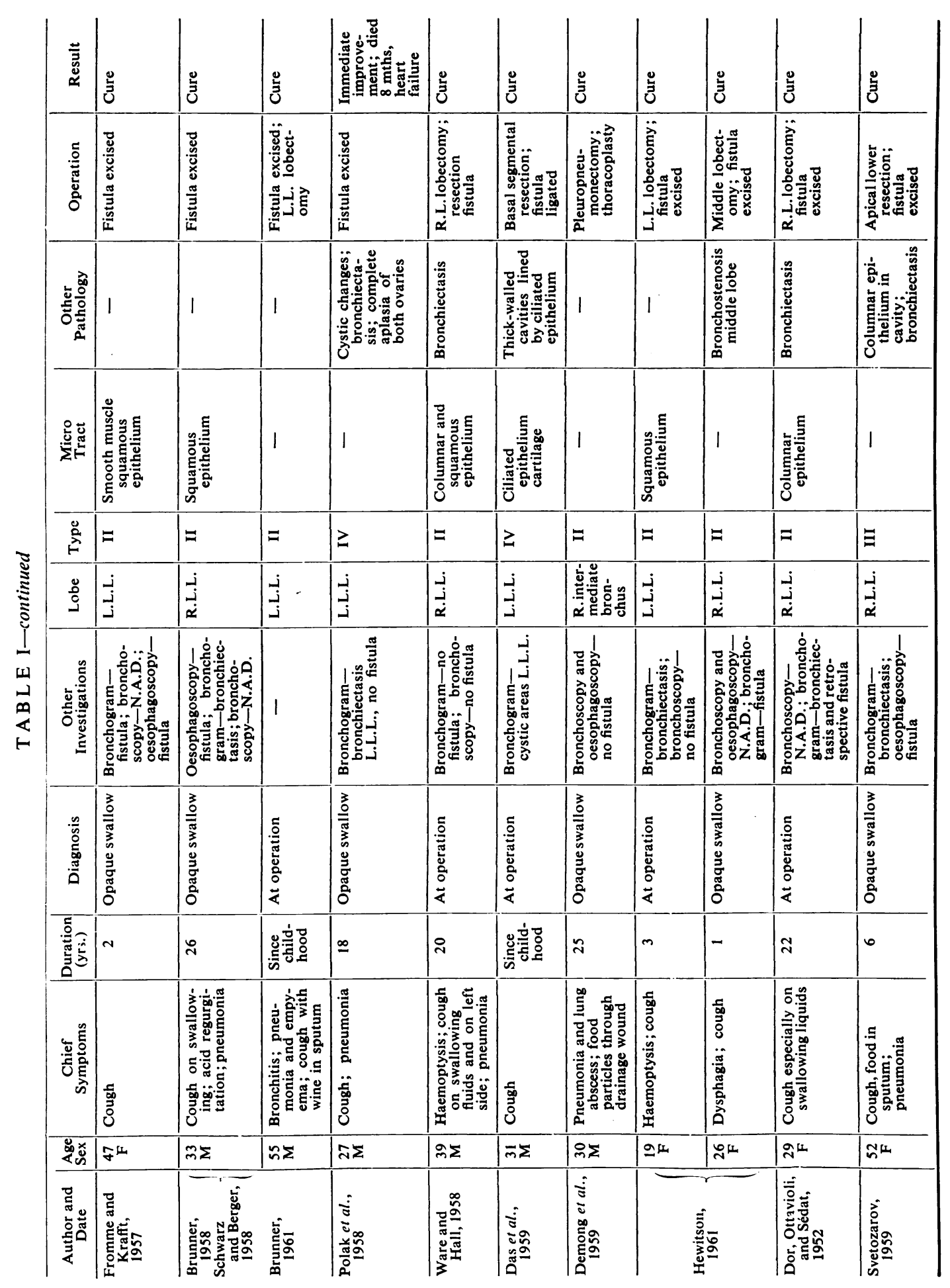

$\underset{\overrightarrow{0}}{\stackrel{3}{+}}$

듬

흠

बำ

$\stackrel{\circ}{\circ}$

W

荠

กิ

N

○

ऐ)

बे

8

列

象

금

킁

宗

量

흠.

§ิ

잉

을

ก

กั

స్ట

ए)

象

$\stackrel{9}{\mathscr{0}}$

꿍

吕

뭉

융

흘 
bronchi diagnosed in adult life, and their details are summarized in the Table.

The congenital nature of a fistula may be assumed if there is no evidence of past or present inflammation around the fistulous track or oesophagus, if there are no adherent lymph nodes, and if there is a mucosa and muscularis mucosae histologically (Brunner, 1961). The absence of inflammation makes dissection of these fistulae simple at operation and virtually excludes a previous inflammatory cause for the lesion.

In this series there were 15 fistulae in which the nature of the mucosa was noted: nine $(60 \%)$ were lined with squamous epithelium, four $(26 \%)$ with columnar, one $(7 \%)$ with transitional, and one $(7 \%)$ with both columnar and squamous epithelium. The fistula led to the right lower lobe in $11(48 \%)$, the left lower lobe in $10(44 \%)$, the middle lobe in one $(4 \%)$, and the right intermediate bronchus in one $(4 \%)$.

Symptoms sometimes begin in childhood, but seldom at birth, as might be expected from their congenital origin. The cause of this delay has been ascribed to the presence of a membrane which subsequently ruptures (Jackson and Coates, 1929), to a proximal fold of oesophageal mucosa initially overlapping the orifice but subsequently becoming less mobile (Negus, 1929), and to the fact that the fistulous track runs upwards and may close during swallowing (Demong, Grow, and Heitzman, 1959) (Fig. 10). None of these theories has any direct evidence in its favour but the second appears to be the most probable, and a distinct fold was seen in the third case described here. In this series the duration of symptoms varied from six months to 50 years, with a mean of 17 years.

I. Fistula runs upwards

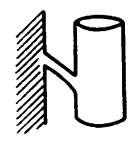

2. Membrane which ruptures

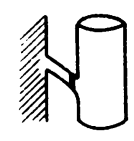

3. Fold of mucous membrane

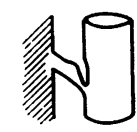

FIG. 10. Reasons for delay in onset of symptoms.
Symptoms may not begin until adult life and are often intermittent (Brunner, 1961). They are usually due to chronic bronchopulmonary suppuration ; cough is almost universal (96\%) and haemoptysis $(17 \%)$ and pneumonia $(56 \%)$ are prominent. Choking on swallowing liquids (or the appearance of food in the sputum) should make the diagnosis obvious, but the symptom, when present $(65 \%)$, is often so mild that it is only elicited in retrospect after the diagnosis has been made by other means (cases 2 and 3). Choking may also be brought on by a change of posture, such as lying on the back or side (cases 1 and 2).

Other oesophageal symptoms are uncommon. The stomach may fill with air on expiration and $N$ cause reflux (case 2) (13\%), and dysphagia is $ᄋ$ sometimes present in the absence of radiological evidence of obstruction (4\%) (Hewitson, 1961). Epigastric discomfort also occurs (13\%).

The fistula itself gives rise to no physical signs, $\vec{\theta}$ but chronic bronchial sepsis and pneumonitis can of cause clubbing of the fingers, basal rhonchi and râles, and pleural effusion.

The diagnosis is usually made by barium swallow $(65 \%)$, when the opaque medium is seen to pass into the lung, outlining the fistulous track. The barium paste should be thin, and the patient $\varnothing$ should be placed in the position in which he finds $\overrightarrow{\overrightarrow{0}}$ his symptoms most marked, as the track may 3 otherwise be missed (Mullard, 1954). A bronchogram rarely demonstrates the fistula but is neces-? sary in the assessment of the extent of bronchial damage. In spite of extensive investigation, the diagnosis may only be made at operation for pul-x monary sepsis $(35 \%)$.

Bronchoscopy and oesophagoscopy sometimes. demonstrate the orifices of the fistula, which areo usually small and only recognized when the exact sites are known (case 3).

The most effective treatment is closure of the fistula and excision of permanently damaged segments of lung. In this series there were six $(26 \%)$ patients in whom the fistula only was closed, $13^{\circ}$ $(57 \%)$ who had lobectomies or segmental resec 0 tions, one $(4 \%)$ who had a sequestrated segment: and three $(13 \%)$ who had pneumonectomies in addition. Cure has been reported after obliteraco tion of the oesophageal end of the fistula with silver nitrate (Clerf, 1933), but this must be an unreliable technique reserved for those patientso who would not stand operation. Thoracotomy division of the fistulous track, closure of its oeso@ phageal end, and lobectomy, if the bronchograns has shown bronchiectasis, will cure all symptoms due to the fistula. In the reported cases treated in this way there have been no operative deaths. 


\section{SUMMARY}

Twenty patients with congenital fistulae between the oesophagus and the lobar bronchi, diagnosed in adult life, have been collected from the literature, and three have been added. A classification is proposed to simplify their description.

The onset of symptoms was usually insidious. The diagnostic symptom of choking on swallowing was present in two-thirds of the patients but was often so mild that it was elicited only in retrospect. A pre-operative diagnosis was usually made by barium swallow, but the condition was first recognized at operation for pulmonary sepsis in a third of the patients.

Treatment involved closure of the fistula and removal of permanently damaged segments of the lung. There was no mortality in this series from the procedure.

Our grateful thanks are due to Sir Thomas Holmes Sellors, Mr. Vernon C. Thompson, and Mr. M. Paneth for permission to publish their cases. We should also like to thank Dr. K. Hinson of the Hospitals for Diseases of the Chest for his assistance with the pathological specimens. We are grateful to Mr. Vince of the Photographic Department of the Royal Marsden Hospital who took the photographs and to Miss Jean Waldron who drew the diagrams.

\section{REFERENCES}

Abrams, H. S. (1954). Esophagorespiratory fistulae. Arch. Otolaryng., 60,371

Berman, J. K., Test, P. S., and McArt, B. A. (1952). Congenital esophagobronchial fistula in an adult. J. thorac. Surg., 24, 493.
Björklund, A. Lindgren, S., and Ranström, S. (1956). Congenital oesophago-bronchial fistula in an adult. Acta chir. scand., 111, 94. Brunner, A. (1958). Fistules oesophago-bronchiques et pulmonaires. Lyon Chir., 54, 536.

- (1961). Oesophago-bronchiale fisteln. Münch. med. Wschr., 103, 2181 .

Clerf, L. H. (1933). Broncho-esophageal fistula; report of case. Ann. Otol. (St. Louis), 42, 920.

Das, J. B., Dodge, O. G., and Fawcett, A. W. (1959). Intralobar sequestration of lung, associated with foregut diverticulum (oesophagobronchial fistula) and an aberrant artery. Brit. J. Surg., 46, 582.

Davidson, J.S. (1956). A case of congenital oesophageal diverticulum, lower accessory lobe, and oesophagobronchial fistula. Ibid., 43, 417.

Demong, C. V., Grow, J. B., and Heitzman, G. C. (1959). Congenita 1 tracheoesophageal fistula without atresia of the esophagus. Amer. Surg., 25, 156.

Dor, Ottavioli, and Sédat (1952). Fistule broncho-oesophagienne découverte au cours d'une lobectomie itérative. Poumon, 8, 445.

Duprez, A., Wittek, F., and Dumont, A. (1956). Acquired and congenital oesophago-bronchial fistulas. Thorax, 11, 249.

Fromme $A$ and Krafft, L. (1957). Utber eine Oesophagus-Bronchusfistel bei einem Erwachsenen (angeboren?). Beihefte zur $Z$ Hals-, Nasen- und Ohrenheilkund., 6, 267.

Guillon, H., Batisse, R., and Mary, A. (1959). Une communication congénitale entre $\mathrm{i}$ 'oesophage et une bronche distale. Ann. Oto-laryng. (Paris), 76, 158.

Hewitson, R. P. (1961). Non-malignant oesophago-bronchial fistula in the adult. S. Afr. med. J., 35, 533.

Jackson, C. and Coates, G. M. (1929). The Nose, Throat and Ear and Their Diseases, p. 1124. Saunders, Philadelphia.

Morton, D. R., Osborne, J. F., and Klassen, K. P. (1950). An apparently congenital broncho-esophageal fistula persistent to adult life. J. thorac. Surg., 19, 811.

Mullard, K. S. (1954). Congenital tracheoesophageal fistula without atresia of the esophagus. Ibid., 28, 39.

Negus, V. E. (1929). Oesophagus from a middle-aged man, showing a congenital opening into the trachea. Proc. roy. Soc. Med., 22, 527.

Polák, E., Levinský, L., Jedliłkka, J., Jedlička, V., and Žák, F. (1958). Operativer Verschluss eines angeborenen Ductus OesophagoBronchialis. Schweiz. Z. Tuberk., 15, 92.

Ribbert, H. (1902). Zur Kenntniss der Tractions-Divertikel des Oesophagus. Virchows Arch. path. Anat., 167, 16.

(1904). Die Traktionsdivertikel des Oesophagus. Ibid., 178, 351. (1906) Noch einmal das Traktionsdivertel des Oesophagus. Ibid., 184, 403 .

Schwarz, E., and Berger, M. (1958). ṫber die oesophago-bronchialen Fisteln. Schweiz. med. Wschr., 88, 688.

Svetozarov, N. M. (1959). O Khirurgu Bronko-pishchevodnykh. svishchei. Vestn. Khir., 82, No. 1, p. 129.

Ware, G. W., and Hall, A. (1958). Congenital tracheoesophageal fistula in the adult. $J$. thorac. Surg., 36, 58.

Wassner, U. J. (1956). Klinik oesophagotrachealer und oesophagobronchialer Fisteln. Thoraxchirurgie, 3, 419. 